\title{
Using Concept Maps for Assessment and Improvement of a Multi-Section In- troduction to Engineering Course
}

\section{Dr. Mary Roth, Lafayette College}

Mary Roth is the Simon Cameron Long Professor of Civil and Environmental Engineering at Lafayette College in Easton, Pennsylvania. She received her degrees in civil engineering from Lafayette College (B.S.), Cornell University (M.S.), and University of Maine (Ph.D.). She joined the faculty at Lafayette in 1991 and her research interests include risk assessment for earth retaining structures, site investigation methods in karst, and engineering pedagogy. She has authored or co-authored over 50 publications and has served as principal or co-principal investigator on nine grants from the National Science Foundation. At Lafayette College Dr. Roth has served as Department Head of Civil and Environmental Engineering, Director of Engineering, and Associate Provost for Academic Operations in addition to multiple faculty committee assignments. She has led campus-wide accreditation and assessment initiatives, implemented new faculty orientation programs, collaborated on the development of multiple proposals to private foundations, and coordinated interdisciplinary academic programs. She has received a number of awards in recognition of her scholarship and teaching including a Fulbright Scholarship in Norway, an American Council of Education Fellowship, and multiple teaching awards. Dr. Roth is a member of ASCE, ASFE, and ASEE. She is a member of Phi Beta Kappa and Tau Beta Pi and is a licensed engineer in the states of Maine and Pennsylvania.

\section{Dr. Kristen L. Sanford Bernhardt, Lafayette College}

Dr. Kristen Sanford Bernhardt is chair of the Engineering Studies program and associate professor of Civil and Environmental Engineering at Lafayette College. Her expertise is in sustainable civil infrastructure management and transportation systems. She teaches a variety of courses including sustainability of built systems, transportation systems, transportation planning, civil infrastructure management, and Lafayette's introductory first year engineering course. Dr. Sanford Bernhardt serves on the American Society of Civil Engineers' Committees on Education and Faculty Development and the Transportation Research Board Committee on Education and Training. She previously has served as vice-chair of the ASCE Infrastructure Systems Committee, chair of the ASEE's Civil Engineering Division, and a member of the Transportation Research Board committees on Artificial Intelligence and Advanced Computing, Asset Management, and Emerging Technology for Design and Construction. She received her Ph.D. and M.S. from Carnegie Mellon University, and her B.S.E. from Duke University. 


\title{
Using Concept Maps for Assessment and Improvement of a Multi-Section Introduction to Engineering Course
}

\begin{abstract}
The authors, professors in civil engineering, teach multiple sections of a required introduction to engineering course at Lafayette College. The course has general student learning outcomes that apply to multiple areas of engineering (e.g., civil engineering, mechanical engineering, chemical engineering, etc.) and were developed by consensus of the engineering departments at the institution. In addition to these general student learning outcomes, more specific student learning outcomes are incorporated into individual sections of the course. These outcomes are developed by the individual faculty member teaching the section and may be related to his/her disciplinary expertise. The courses that serve as the foundation for the work presented in this paper have student learning outcomes associated with civil engineering.

Because of the general nature of most introduction to engineering courses, comparison of assessment outcomes across different course sections can be difficult, and that difficulty can hinder productive discussions across disciplines and the development of recommendations for course improvements. We have used a simple concept map assignment, given on the first and last day of each course, to evaluate student learning outcomes and as a basis for analysis of multiple sections of the course within civil engineering and the development of recommendations for course improvements in that area. The work presented in this paper is anticipated to serve as the foundation for a future project assessing sections of the course across multiple engineering areas.
\end{abstract}

\section{INTRODUCTION}

Introduction to Engineering courses are offered at many colleges and universities. The courses can take a wide variety of different forms, both in terms of number of credits and number of semesters, and in terms of course objectives and content. Some courses attempt to introduce students to a variety of engineering disciplines, while others focus on a single discipline. Many of these courses have been documented in ASEE conference proceedings over the years.

Recently, Reid and Reeping ${ }^{1}$ developed and implemented ${ }^{2}$ a classification scheme to allow comparison of these courses. The top level of their scheme includes communication, design "latent curriculum"/professional skills, engineering profession, academic advising, math skills, engineering technology/tools, and global interest. This scheme provides a basis for comparison of desired outcomes across courses and across institutions.

We were interested in comparing changes in student understanding related to engineering and design over the course of the semester in two separately developed modules for the Introduction to Engineering course at our institution. We designed a pilot study in which students developed concept maps for "Engineering" at the beginning and end of the module, and we compared the 
maps using a jointly developed rubric. This paper provides a brief explanation of concept maps as well as descriptions of the particular course studied, the methodology, the findings, and the lessons learned.

\section{BACKGROUND}

\section{Concept Maps}

Concept maps are a visual method of organizing information. They were first developed and used as a pedagogical tool by Stewart et al. $^{3}$, and researchers have since further developed and refined the method for use in teaching, learning, research, and assessment ${ }^{\text {e.g., } 4}$. Figure 1 shows a concept map developed by Novak and Canas $^{5}$ that defines the structure and characteristics of concept maps.

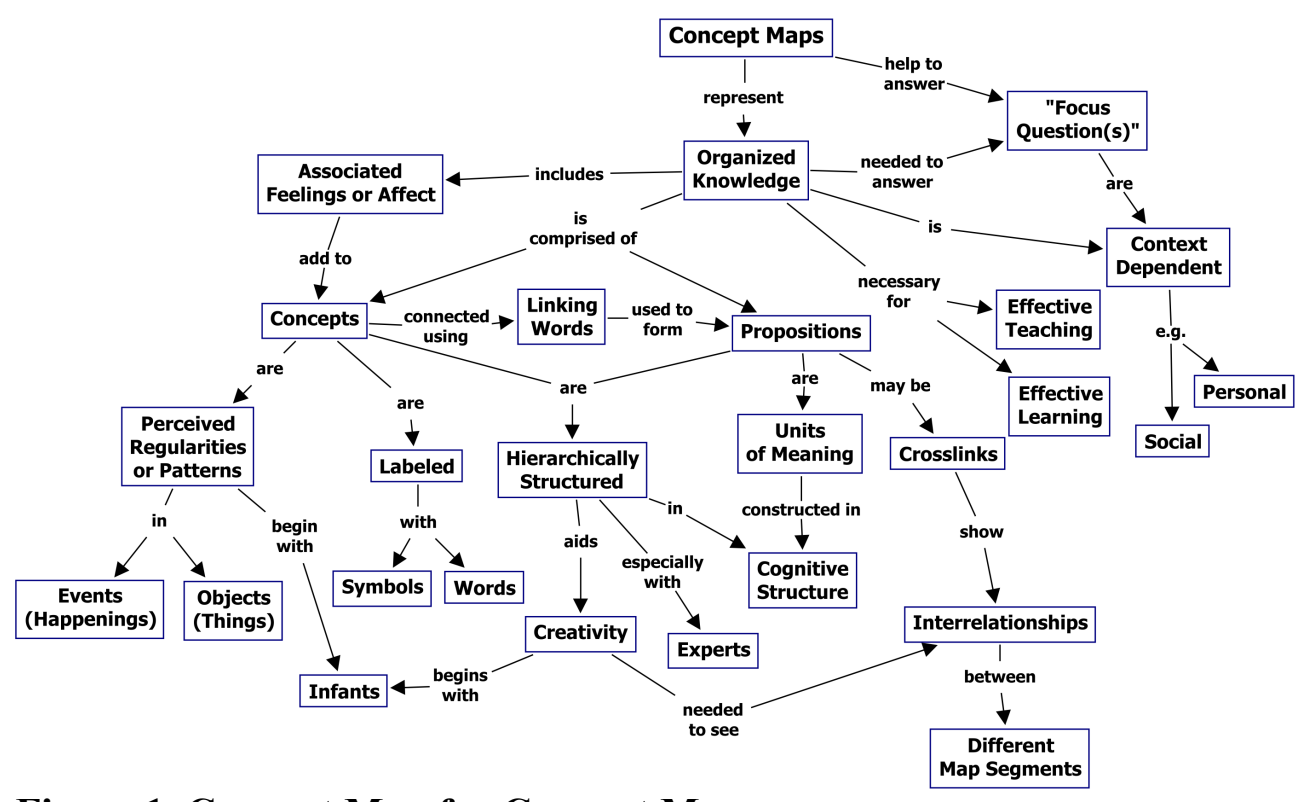

Figure 1. Concept Map for Concept Maps

The use of concept maps as an assessment tool has two elements: assigning students the development of a map to demonstrate their knowledge and using a rubric or grading system to evaluate the students' knowledge. Students can be asked to develop a concept map with paper and pencil or by using specialized software, and scoring can be holistic, relational, structural, or by methods specific to a particular application ${ }^{6}$. Stoddart et al. ${ }^{7}$ provide an overview of the use of concept maps to assess student learning in science, and Carey ${ }^{8}$ was one of the first researchers to compare concept maps produced by students over time as a means to understand how students' knowledge develops.

In engineering education, concept maps have been used to assess knowledge integration across an engineering program ${ }^{9}$, conceptual understanding in a engineering dynamics course ${ }^{10}$, and student preconceptions in an introductory transportation engineering course ${ }^{11}$, among other applications. 


\section{Introduction to Engineering Course at Lafayette College}

An Introduction to Engineering course has existed in various forms at Lafayette College for over 30 years. The student learning outcomes for the course have evolved, but the course has always been designed as a way to help students learn about the different types of engineering offered (there are four ABET-accredited BS degrees as well as an AB degree). In fall of 2013, a new model of the course was initiated in which each faculty member teaching the course develops a 7-week module that relates to his or her discipline and meets a series of outcomes that have been agreed to by the Engineering Division. These modules are developed independently by the faculty member teaching the course and there is no requirement to follow a standard format or to use common materials. Each student takes two modules over the course of the semester. In addition, students receive instruction in engineering graphics, and a co-curricular component introduces students to all five degree programs. The common course outcomes are:

Upon completion of this course, students will:

- recognize that engineering at [Institution] and beyond is innovative and exciting.

- understand the engineering design process.

In support of the outcomes listed above, students will:

- have had an introductory design experience

- have had experiences using engineering equipment, tools, software, and hardware appropriate to the topic of the course

- have a working knowledge of engineering graphics and basic CAD skills

- have an introductory understanding of the societal context of engineering relevant to the topic of the course

- gain experience in visually and orally conveying engineering information, e.g., create and present a poster

In fall of 2015, we (both faculty members in the Department of Civil and Environmental Engineering) taught separate sections of the course (one taught Section 4 and the other Sections 5 and 6). Although the context for all three sections was civil engineering and addressed the common course outcomes listed above, we developed and implemented different course structures and module-specific outcomes for our sections. These modules are described below.

Designing the Sustainable City (Section 4) introduces design in the context of sustainable urban infrastructure. Design is introduced through design thinking, including the Stanford Design School's Wallet Project

(https://dschool.stanford.edu/groups/designresources/wiki/4dbb2/The_Wallet_Project.html), with a focus on the importance of developing empathy as an essential component of the design process. The module is based on a series of small projects interspersed with mini-lectures and discussions. Students take two walking field trips in our city to explore the existing infrastructure, and the local Director of Public Works visits twice with the students to help them develop an understanding of the challenges and constraints in building and maintaining urban infrastructure. The module-specific outcomes, which are in addition to the overall course outcomes, are:

- Describe and discuss ways in which engineering has changed / has the potential to change the world; 
- Explain one approach to the engineering design process and apply it;

- Discuss ways in which designing civil infrastructure differs from design of other types of engineering artifacts;

- Discuss what it means for a city to be sustainable and apply these considerations in the design process; and

- Communicate graphically, in writing, and orally regarding the above.

Geotechnical Engineering: Design, Risk, and Judgment (Sections 5 and 6) introduces design in the context of geotechnical engineering. Students also complete a Stanford Design School design thinking exercise and learn about construction in urban environments, geotechnical materials, and design principles for simple foundations. The final three weeks of the module include a team project in which students work in pairs and identify a distressed structure on campus, hypothesize potential causes for the distress, develop estimates of failure risk, and prepare a final report and presentation on their project. The module specific outcomes are:

- Demonstrate a basic understanding of the field of geotechnical engineering,

- Develop a simple model related to the geotechnical performance of a structure,

- Conduct a simple analysis of risk; and

- Write a geotechnical report in standard format.

\section{METHODOLOGY}

We gave the same concept map assignment to all students in their separate course sections at the beginning and end of the module (Figure 2). The pre-assignment was given in class on the first day of the module in all three sections; the post-assignment was completed in class on the penultimate day of class for Section 4 and the last day of class for Sections 5 and 6. Students were asked to draw the maps by hand and were given no additional instruction in the design of concept maps beyond the instructions on the handout. The assignment was given to all students in Sections 5 and 6 during both 7-week modules (a total of 57 students) and to all students in Section 4 during the second 7 -week module (a total of 18 students).

We developed a common rubric for assessing the maps based on what we expected students would associate with "Engineering" after completing one of the modules (Figure 3) and in light of the learning outcomes associated with the course. In particular, we were interested in changes in students' conceptions of the relationship between engineering and design, the nature of design, and disciplines within engineering, as well as their attitude toward engineering more broadly. To normalize their use of the rubric, the instructors separately scored pairs of pre- and post- concept maps for a random sample of four students and then compared the scoring. As a result, we refined the rubric slightly and synchronized our interpretation of terms in the rubric. Both of us then used the rubric to score the pre- and post- concept maps for the students in all three sections and recorded our results. 


\section{Concept Map: What is engineering?}

Concept maps are drawings that illustrate relationships between ideas and/or concepts and are often used by engineers to organize their knowledge of a subject-i.e., they are a visual method of organizing information. In a concept map, each word or phrase connects to another and links back to the original idea or concept.

An example of a concept map is shown below.

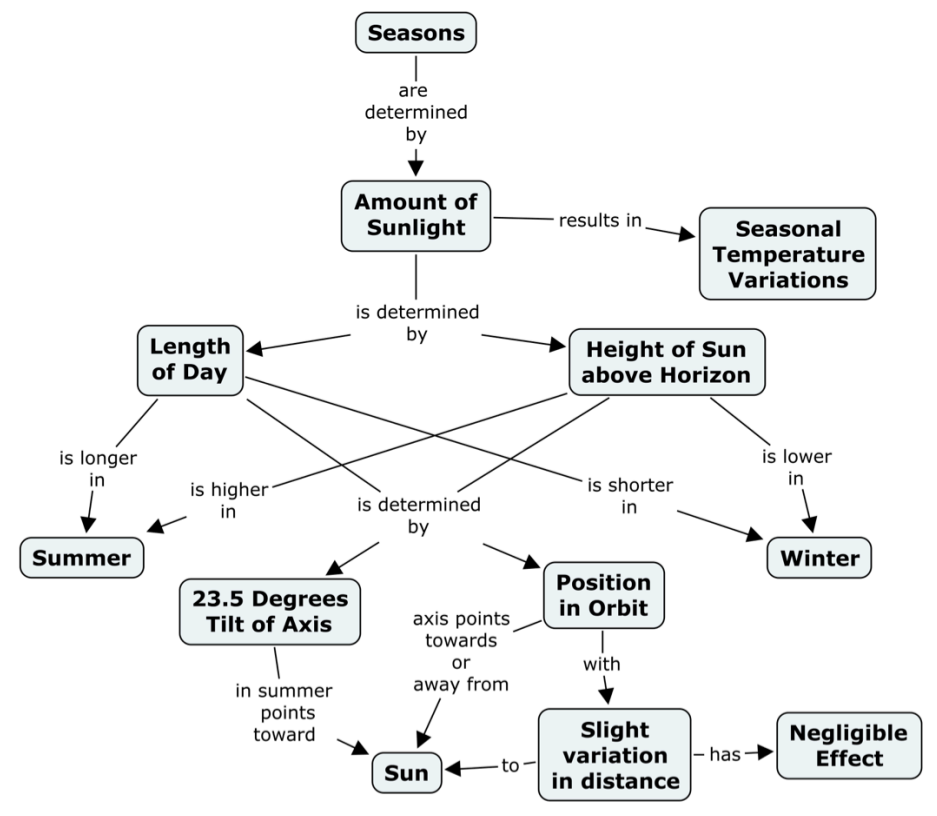

Your task is to develop a concept map for "Engineering" (i.e., a map that in visual terms answers the question, "What is engineering?")

- Brainstorm for a few minutes and, on the back of this paper, write down terms and short phrases that are connected to your current understanding of engineering.

- On a new sheet of paper, draw a concept map based on your brainstorming, placing "Engineering" at the center or top of the drawing and drawing lines to other related concepts.

- After you have sketched in the primary associations, move on to add secondary or tertiary levels of association (or more), if appropriate.

- Determine the ways in which the various concepts are related to each other and write those types of relations on the lines connecting the concepts.

- Put your name on the map and turn it in!

References

- Using Concept Maps. Accessed: 25 June 2015 https://www.cmu.edu/teaching/assessment/assesslearning/conceptmaps.html

- Kathy Schrock's Guide to Everything, Accessed: 25 June 2015 http://www.schrockguide.net/concept-mapping.html

Figure 2. Concept Map Assignment 


\begin{tabular}{|l|l|l|l|}
\hline \multirow{2}{*}{ Element } & Score & $\mathbf{1}$ \\
\cline { 2 - 4 } & $\mathbf{0}$ & $\begin{array}{l}\text { 1 } \\
\text { pesign is an integral engineering } \\
\text { present in map but } \\
\text { have few if any } \\
\text { meaningful } \\
\text { connections }\end{array}$ & $\begin{array}{l}\text { No mention of } \\
\text { design concepts } \\
\text { present in map and } \\
\text { have multiple } \\
\text { connections }\end{array}$ \\
\hline $\begin{array}{l}\text { Design requires } \\
\text { empathy with users }\end{array}$ & $\begin{array}{l}\text { No indication of } \\
\text { recognition of need } \\
\text { for empathy }\end{array}$ & $\begin{array}{l}\text { Map includes } \\
\text { minimal recognition } \\
\text { of need for empathy }\end{array}$ & $\begin{array}{l}\text { Map indicates a clear } \\
\text { connection between } \\
\text { empathy and the } \\
\text { design process }\end{array}$ \\
\hline $\begin{array}{l}\text { Design as an } \\
\text { iterative process }\end{array}$ & $\begin{array}{l}\text { Design is not } \\
\text { conveyed as being a } \\
\text { process }\end{array}$ & $\begin{array}{l}\text { Design is conveyed } \\
\text { as being a process } \\
\text { but is not shown as } \\
\text { iterative }\end{array}$ & $\begin{array}{l}\text { Design is conveyed } \\
\text { as being an iterative } \\
\text { process }\end{array}$ \\
\hline $\begin{array}{l}\text { Engineering is } \\
\text { innovative/exciting }\end{array}$ & $\begin{array}{l}\text { No use of words } \\
\text { displaying affect }\end{array}$ & $\begin{array}{l}\text { Limited use of words } \\
\text { displaying affect }\end{array}$ & $\begin{array}{l}\text { Map uses terms } \\
\text { displaying affect to } \\
\text { convey innovation or } \\
\text { excitement }\end{array}$ \\
\hline $\begin{array}{l}\text { Non-trivial } \\
\text { understanding of at } \\
\text { least one area of } \\
\text { engineering }\end{array}$ & $\begin{array}{l}\text { No indication of } \\
\text { depth of } \\
\text { understanding in } \\
\text { any area of } \\
\text { engineering }\end{array}$ & $\begin{array}{l}\text { Limited indication of } \\
\text { depth of } \\
\text { understanding in at } \\
\text { least one area }\end{array}$ & $\begin{array}{l}\text { Multiple map links } \\
\text { indicate depth of } \\
\text { understanding of at } \\
\text { least one area of } \\
\text { engineering }\end{array}$ \\
\hline $\begin{array}{l}\text { Understanding of } \\
\text { multiple areas of } \\
\text { engineering }\end{array}$ & $\begin{array}{l}\text { No indication of } \\
\text { recognition of basic } \\
\text { fields of engineering }\end{array}$ & $\begin{array}{l}\text { Indications of basic } \\
\text { fields of engineering } \\
\text { present but limited } \\
\text { elaboration provided }\end{array}$ & $\begin{array}{l}\text { Indications of basic } \\
\text { fields of engineering } \\
\text { present and } \\
\text { connections indicate } \\
\text { non-trivial } \\
\text { understanding of } \\
\text { multiple areas }\end{array}$ \\
\hline
\end{tabular}

\section{Figure 3. Concept Map Evaluation Rubric}

\section{FINDINGS}

The results of our reviews of student concept maps were averaged for each section of the course and summarized using radar charts shown in Figures 4 and 5. Two sets of examples of student work are included in the Appendix - one set of maps shows substantial change in the concept map from pre- to post- and the second shows little difference.

Figure 4 summarizes the results for four modules of the course taught by the same instructor. Modules 5A and 6A were taught during the first seven weeks of the semester (i.e., these are results from students in their first module of the course) and Modules $5 \mathrm{~B}$ and $6 \mathrm{~B}$ were taught during the second seven weeks of the course (i.e., after the students had completed a module in an engineering discipline outside of civil engineering). Differences between the pre- and post- 
module plots are seen in three of the four sections (section 6B shows little difference between pre- and post- module maps) with the general pattern of change for the remaining three sections being similar (i.e., these sections show increased understanding of design as an integral part of engineering, design as an iterative process, and increased understanding of one area of engineering). There is very little difference observed in the pre-module plots for modules taught in the first seven weeks (5A and 6A) and those taught in the second seven weeks (5B and 6B). Because all students in each section of the course were included in the analysis, no statistical analysis (e.g., analysis concerning statistical significance of the results) was necessary.

Figure 5 summarizes the results for modules taught by two different instructors. Module 4B was taught by one of us and Modules 5B and 6B were taught by the other (these are the same results shown in Figure 4). The differences in these plots are more easily observed and reflect the different module designs used by the instructors. The instructor for module $4 \mathrm{~B}$ focused on design and the role of empathy. The instructor for modules $5 \mathrm{~B}$ and $6 \mathrm{~B}$ focused on a particular area of engineering (geotechnical engineering), including a three-week project related to that area.

\section{Section $5 A$}

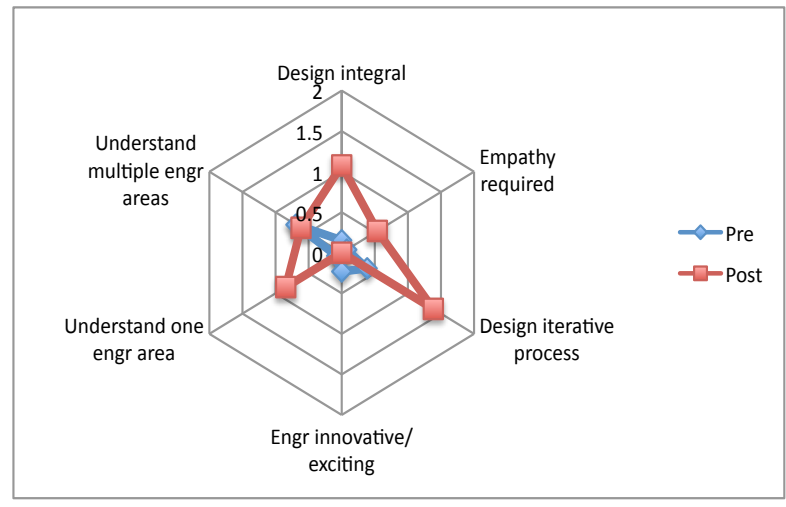

Section 5B

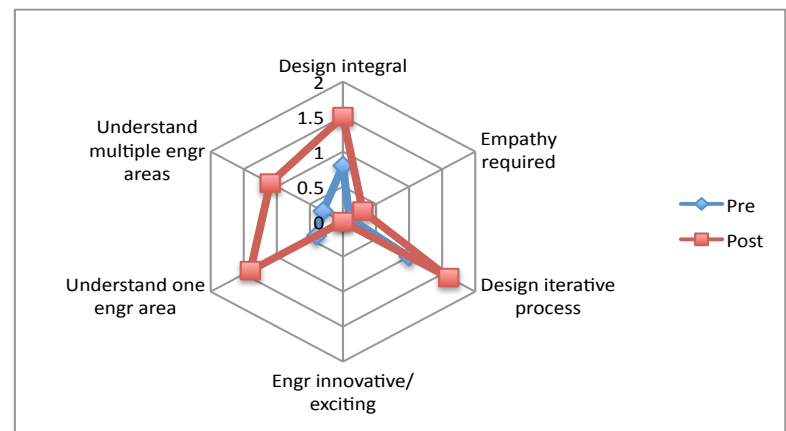

Section 6A

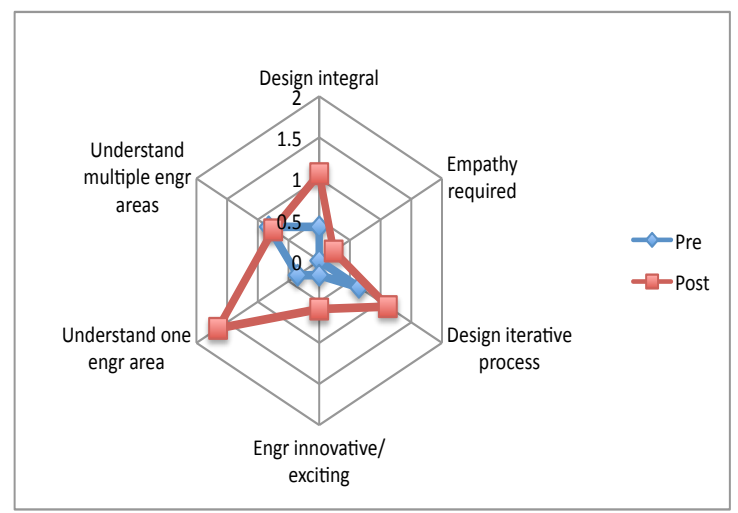

Section 6B

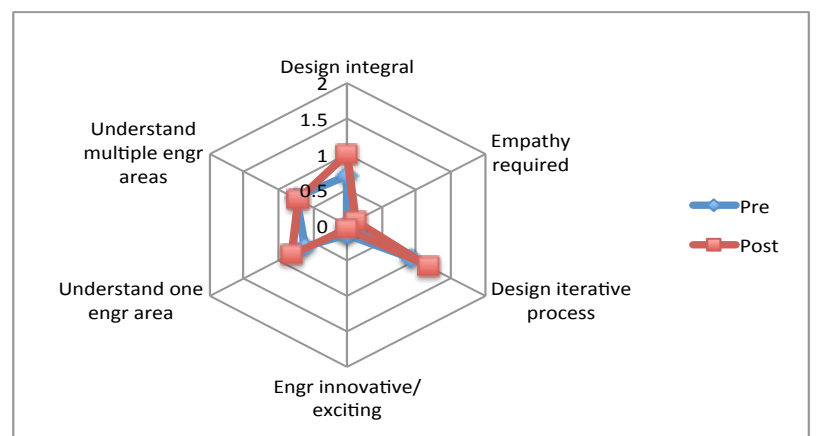

Figure 4. Results for Sections 5A and 6A (first module) and Sections 5B and 6B (second module) 


\section{Section 4B}

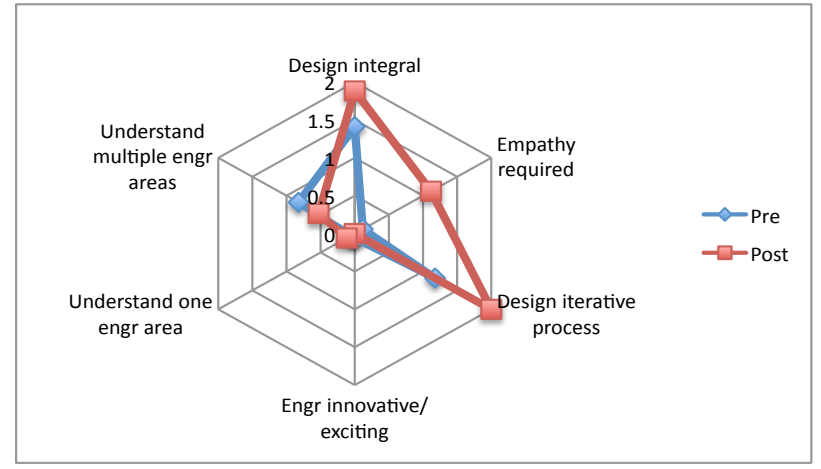

\section{Section 5B}

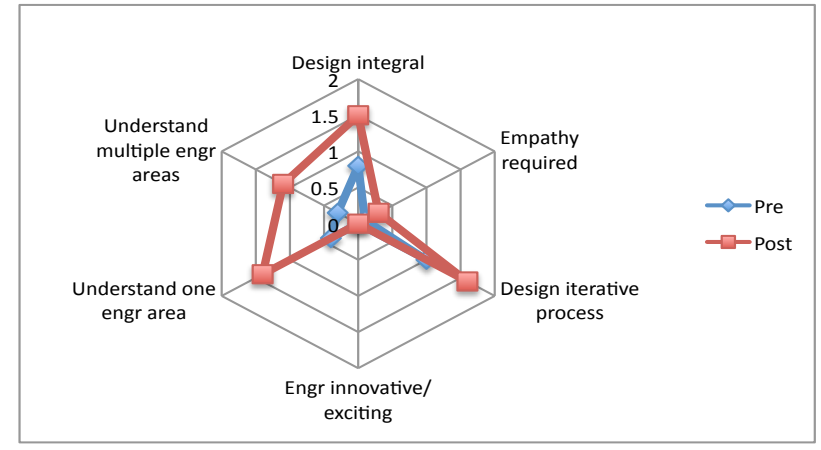

\section{Section 6B}

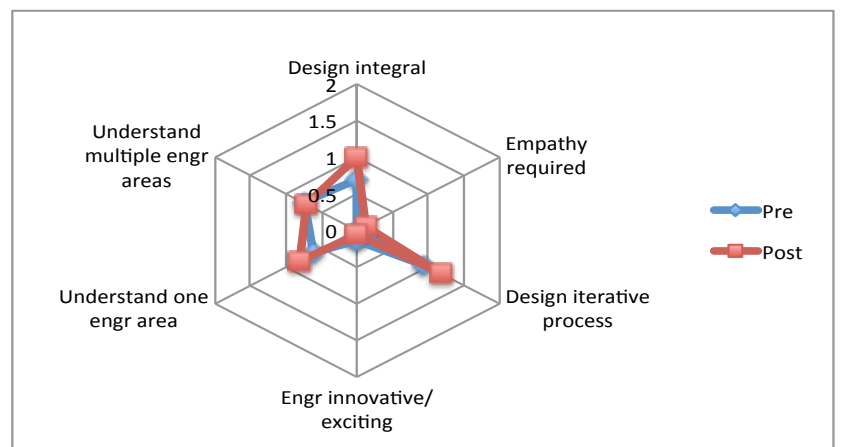

Figure 5. Results for Sections 4B, 5B, and 6B

\section{LESSONS LEARNED}

In contrast to a survey of student perceptions of their understanding (an approach that was not used in this study), the concept maps the students were asked to develop provide direct assessment of how students' understanding develops over a course, or part of a course - a significant benefit of the approach. We used approximately 50-60 minutes of class time for development of the maps (20 minutes for the pre-maps and 30 for the post-maps), so it did not require a substantial amount of class time. Rubric development and scoring also did not require substantial investments of time from the faculty involved. 
We found the process - that is the concept map exercise, the development of the rubric for assessing the concept maps, the assessment itself, and the ensuing discussion - valuable as a tool for stimulating thinking about each of the modules individually and comparing changes in student understanding across modules. The latter creates a basis for meaningful discussion of how the different learning outcomes and associated course activities lead to differences in student understanding.

Based on the work presented here, we recommend the use and assessment of concept maps as a simple approach to compare sections of courses in which faculty members have significant autonomy regarding course content and pedagogical approach and to stimulate faculty discussion regarding future course development.

\section{REFERENCES}

1. Reid, K., and Reeping, D. (2014). A Classificaton Scheme for 'Introduction to Engineering' Courses: Defining First-Year Courses Based on Descriptions, Outcomes and Assessment. Proceedings 2014 ASEE Annual Conference \& Exposition. Indianapolis, IN, June.

2. Reeping, D., and Reid, K. (2015). Application of and Preliminary Results from Implementing the First-Year Introduction to Engineering Course Classification Scheme: Course Foci and Outcome Frequency. Proceedings 2015 ASEE Annual Conference \& Exposition, Seattle, WA, June.

3. Stewart, J., Van Kirk, J., and Rowell, R. (1979). Concept maps: a tool for use in biology teaching. The American Biology Teacher, 41 (3), 171-175.

4. Novak, J.D. (1998). Learning Creating, and Using Knowledge: Concept Maps as Facilitative Tools in Schools and Corporations. Lawrence Erlbaum Associates, Inc., Mahway, NJ.

5. Novak, J.D., and Canas, A. J. (2008). The Theory Underlying Concept Maps and How to Construct and Use Them, Florida Institute for Human and Machine Cognition Technical Report, IHMC CmapTools 2006-01 Rev 2008-01.

6. Ingec, S. K. (2009). Analysing Concept Maps as an Assessment Tool in Teaching Physics and Comparison with Achievement Tests. International Journal of Science Education, 31 (14), 1897-1915.

7. Stoddart, T., Abrams, R., Gasper, E., and Canaday, D. (2000). Concept maps as assessment in science inquiry learning - a report of methodology. International Journal of Science Education, 22 (12), 1221-1246.

8. Carey, S. (1986). Cognitive science and science education. American Psychologist, 41, 11231130.

9. Besterfield-Sacre, M., Gerchak, J., Lyons, M., Shuman, L. J., and Wolfe, H. (2004). Scoring Concept Maps: An Integrated Rubric for Assessing Engineering Education, Journal of Engineering Education, April, 2004.

10. Fang, N. (2015). Using Student-Generated Concept Maps to Assess Students' Conceptual Understanding in a Foundational Engineering Course, Proceedings 2015 ASEE Annual Conference \& Exposition. Seattle, WA, June.

11. Mladenovic, M. N., Mangaroska, K., and Abbas, M. M. (2016). Assessment of Students' Preconceptions in an Introductory Transportation Engineering Course: Case Study at Virginia Tech, Journal of Professional Issues in Engineering Education and Practice, 05016002 . 


\section{APPENDIX}

Figures A1 and A2 show concept maps developed by a student (Student 1) whose understanding did changed substantially over the course, while Figures A3 and A4 were drawn by a student (Student 2) whose understanding changed less dramatically over the course.

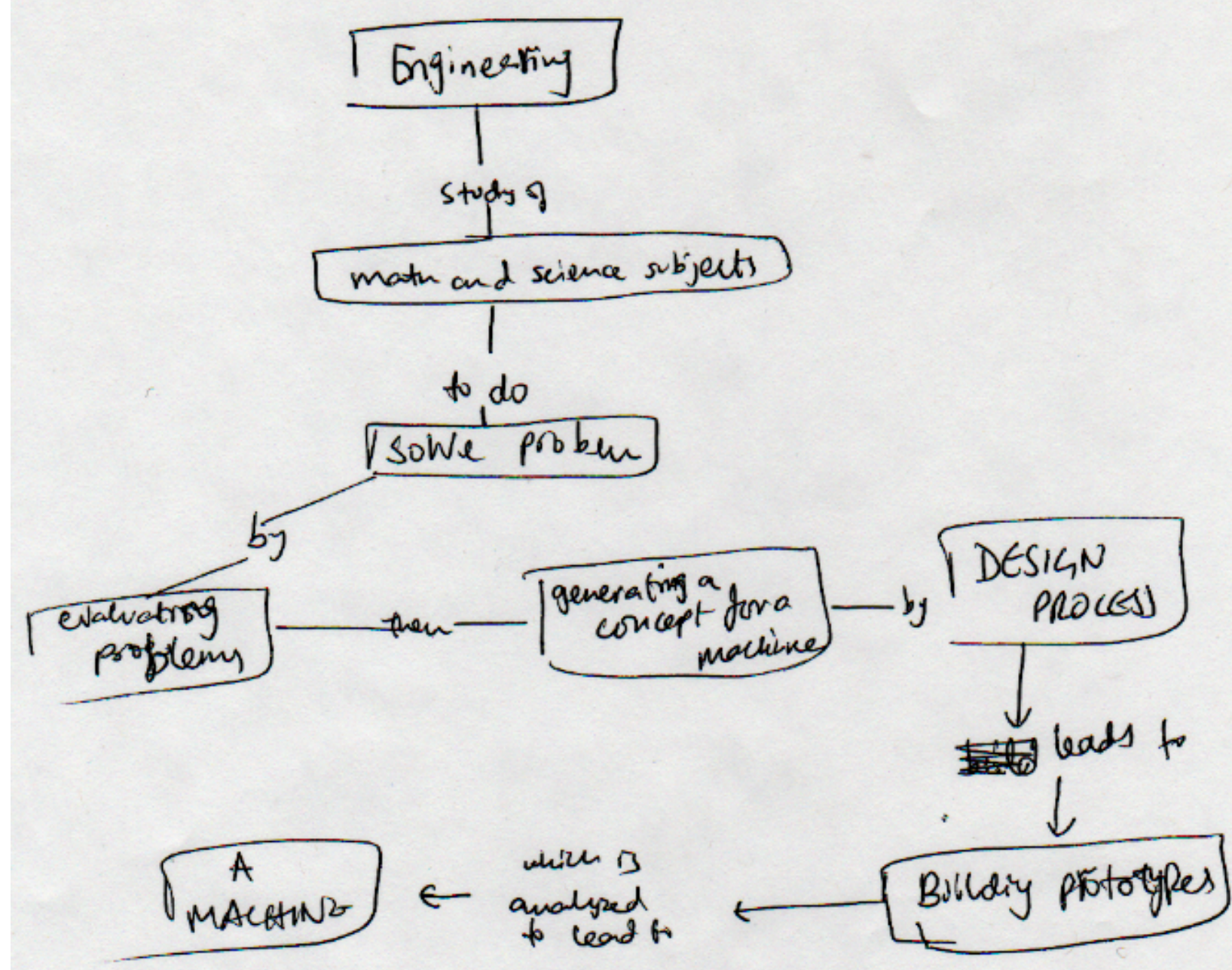

Figure A1. Pre-Course Concept Map for Student 1 


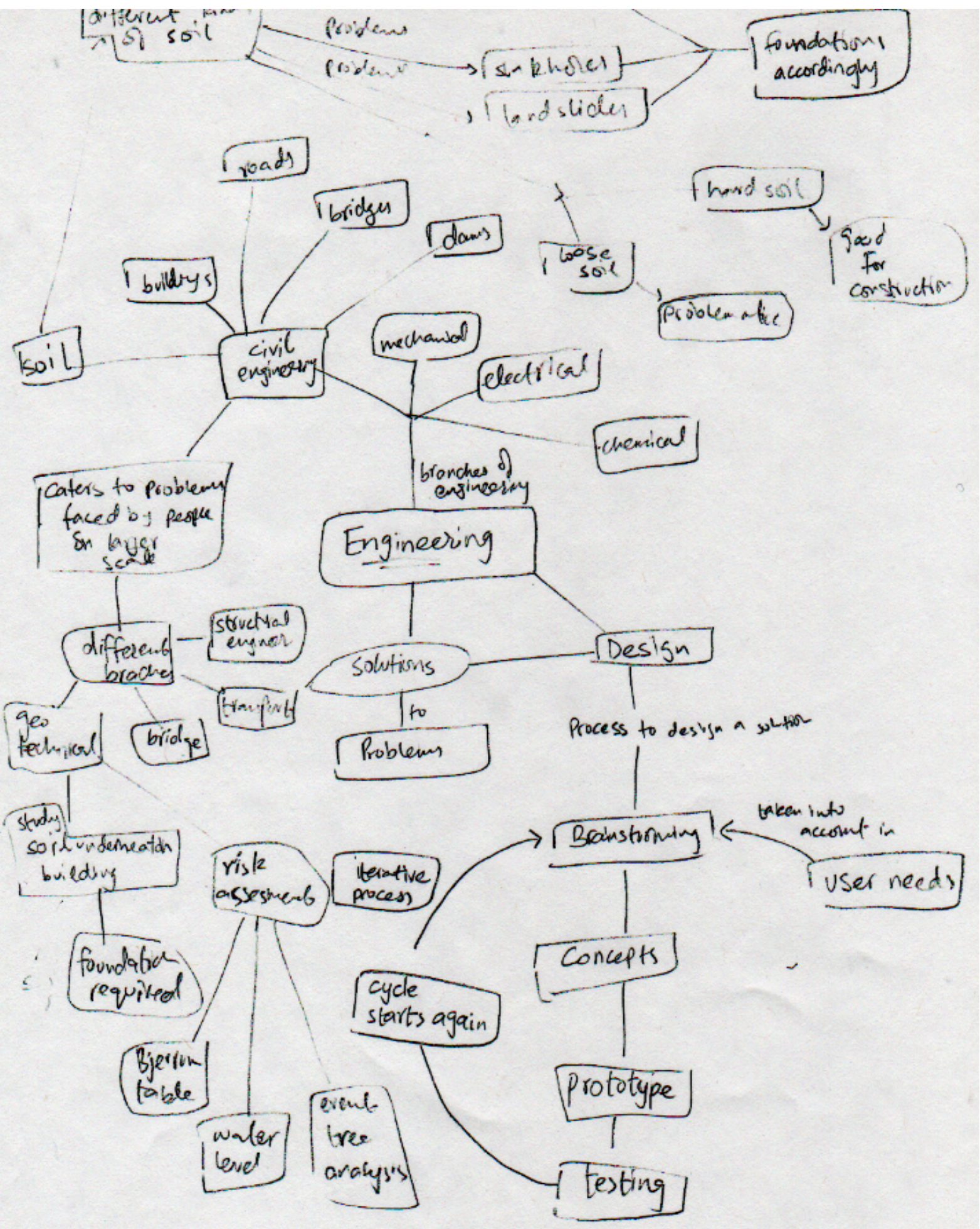

Figure A2. Post-Course Concept Map for Student 1 


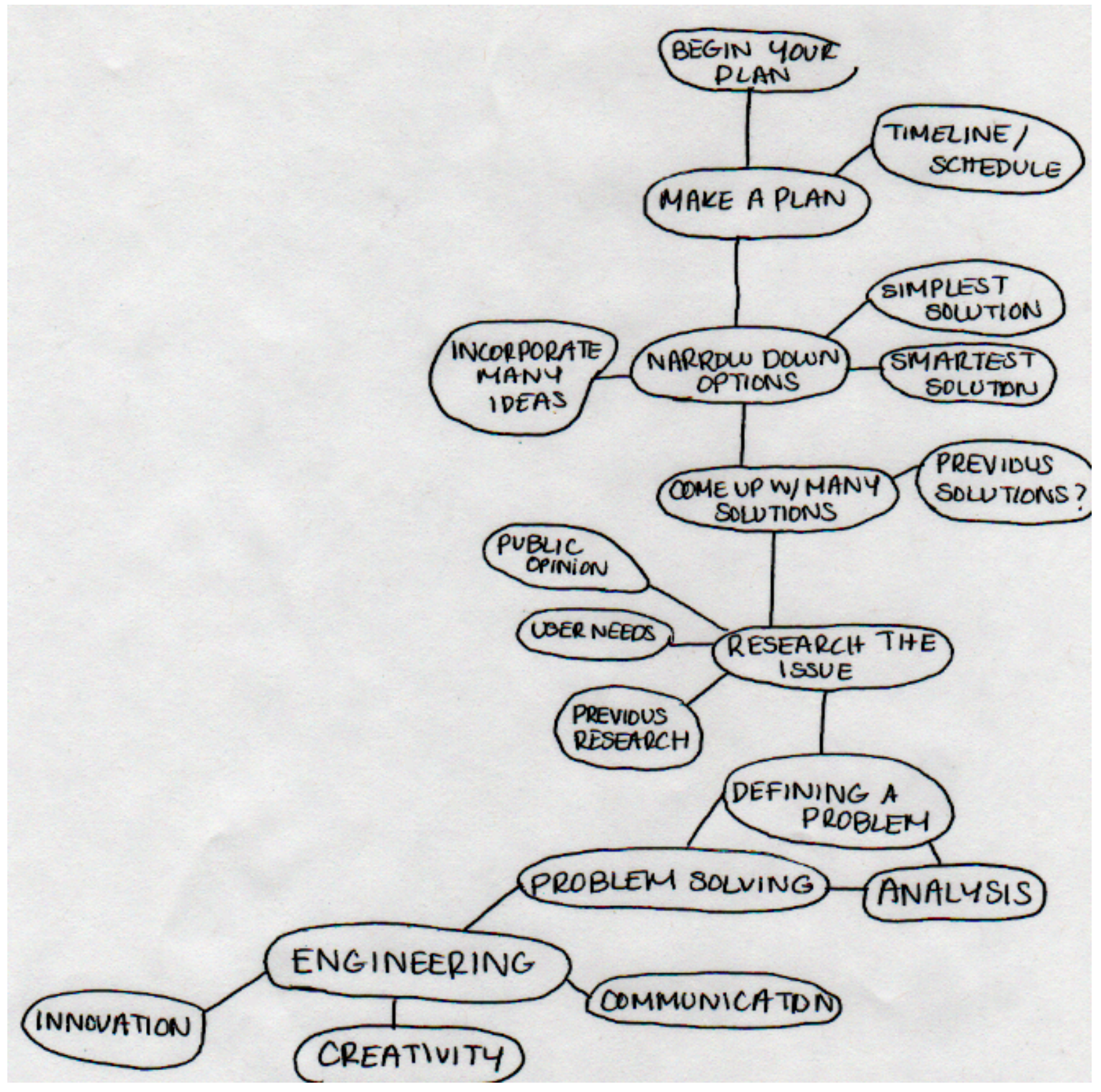

Figure A3. Pre-Course Concept Map for Student 2 


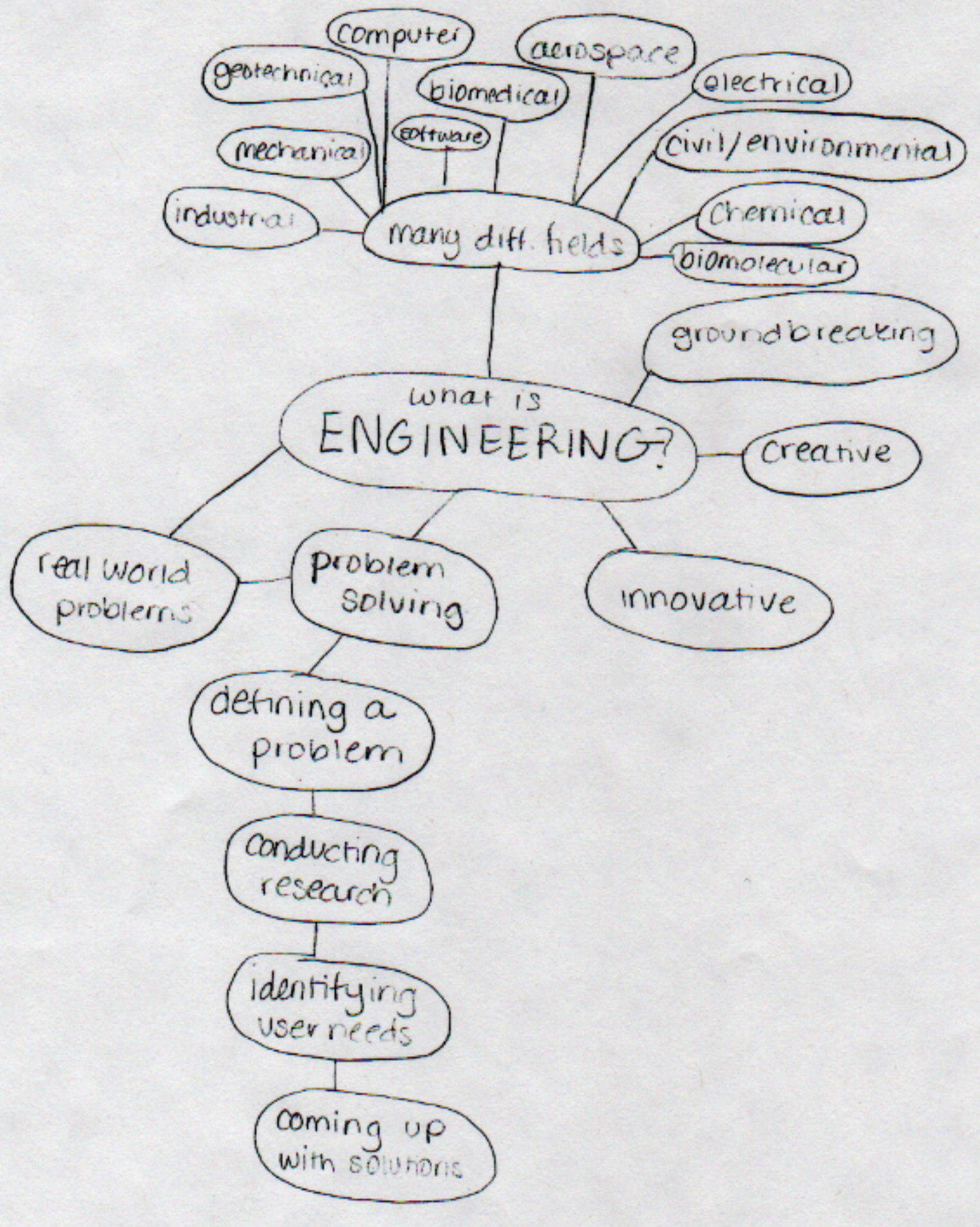

Figure A4. Post-Course Concept Map for Student 2 